\title{
XXIX. The thermal effect due to reversals of magnetization in soft iron
}

\section{A. Tanakadaté}

To cite this article: A. Tanakadaté (1889) XXIX. The thermal effect due to reversals of magnetization in soft iron, Philosophical Magazine Series 5, 28:172, 207-218, DOI:

10.1080/14786448908619858

To link to this article: http://dx.doi.org/10.1080/14786448908619858

Published online: 08 May 2009.

Submit your article to this journal ¿

Џll Article views: 2

Q View related articles $ᄃ$ 


\section{[ 207 ]}

XXIX. The Thermal Effect due to Reversals of Magnetization in Soft Iron. By A. Tanakadaté, Rigakusi*.

[Plates VI.-VIII.]

THEE following experiment on the measurement of the heat due to the reversals of magnetization in soft iron wire was carried out in the Physical Laboratory of the Glasgow University during the summer months of 1888 . The method pursued is due to Sir William Thomson, in accordance with whose instructions the work was undertaken.

Cotton-covered soft iron wire, of $\cdot 115$ centim. diameter, was coiled upon a specially prepared wooden groove. The ends of the wire were insulated from each other; and the bundle was tied at several places with fine silk thread to keep its shape, and when the wooden frame was removed the coil of the wire was left in shape of an anchor-ring. The object of thus building the ring with insulated wire instead of solid mass was to reduce the Foucault current in the substance of iron when an alternating current is passed in the magnetizing coil.

The ring thus formed was now wound uniformly over with No. 16 silk-covered copper wire in two layers, a thermoelectric junction consisting of platinoid and copper being placed upon the outer surface of the ring before winding. The principal dimensions of the ring were as follows :-

Diameter of the soft iron wire . . . . 0.115 centim.

Number of turns of the soft iron wire in the ring . . . . . . . . . . . 130

Total number of turns of copper wire in the magnetizing solenoid . . . . . 177

Internal diameter of the ring . . . . 6 centim.

External diameter of the ring. . . . . 10 ",

Mean . . . . . . . . . . . 8 "

Mean strength of magnetizing field due to 1 ampere through the coil

$$
=4 \pi \frac{177}{8 \pi \times 10}=8.85 \text { C.G.S. }
$$

A wooden ring, of very nearly the same size and shape as that of the iron wire, was turned and wound similarly with the same silk-covered copper wire, total number of turns, however, being 174 . The other junction of the same thermoelectric couple was laid on the surface of this wooden ring in the same way as the other junction was disposed with regard to the iron ring, so that the platinoid wire stretched between the two rings, and copper wire from the two rings led to terminals of a mirror-galvanometer, as in the diagram.

The magnetizing coils of the two rings were joined in series,

* Communicated by Sir William Thomson. 
and led to an alternating-commutator through an idiostatic galvanometer. The alternator was driven by a clockwork.

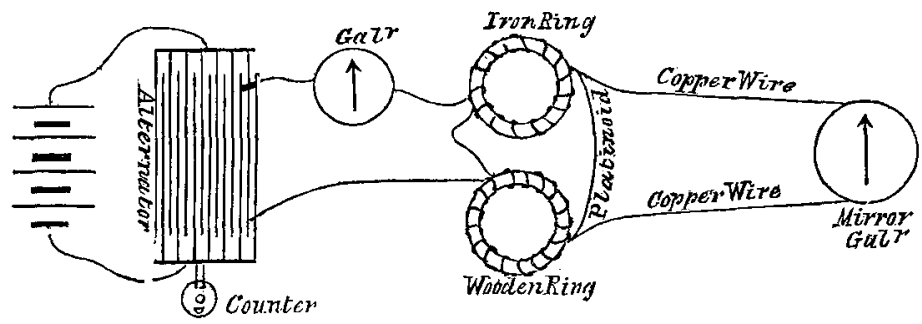

It had forty teeth on each side, so that one revolution of it made forty complete reversals of magnetization in the iron ring inside the core. The current was supplied from secondary batteries, and its strength was adjusted by means of resistances, which were in most cases Edison lamps joined in multiple are.

The thermoelectric constant of the junctions was determined by heating the iron ring in a specially prepared sand-bath, while the wooden ring was kept at the temperature of the room. The sand-bath was first heated by a gas-flame up to about $60^{\circ} \mathrm{C}$., and left to cool slowly. Several simultaneous readings of the galvanometer-deflexion and temperaturedifference of the junctions were taken, and the value of the difference of temperature corresponding to one division of the galvanometer-deflexion was deduced as follows :-

Determination of Thermoelectric Constant (April 5, 1888).

\begin{tabular}{|c|c|c|c|c|c|}
\hline Time. & $\begin{array}{l}\text { Temp. of } \\
\text { iron ring. }\end{array}$ & $\begin{array}{l}\text { Temp. of } \\
\text { wooden } \\
\text { ring. }\end{array}$ & $\begin{array}{l}\text { Difference } \\
\text { of tempe- } \\
\text { rature. }\end{array}$ & $\begin{array}{l}\text { Galvanometer- } \\
\text { deflexion. }\end{array}$ & $\begin{array}{c}\text { Difference of } \\
\text { temperature } \\
\text { corresponding } \\
\text { to one division } \\
\text { of galvano- } \\
\text { meter-deflex- } \\
\text { ion. }\end{array}$ \\
\hline $\begin{array}{rr}\mathrm{h} & \mathrm{m} \\
12 & 0\end{array}$ & 53.60 & $14^{\circ} \cdot 4 \mathrm{C}$. & $39.2 \mathrm{c}$. & 489 & ${ }^{\circ} \cdot 08020$ \\
\hline 15 & $42 \cdot 4$ & $15 \cdot 2$ & $27 \cdot 2$ & 343 & .0794 \\
\hline 127 & $38 \cdot 8$ & $15 \cdot 1$ & $23 \cdot 7$ & 297 & $\cdot 0798$ \\
\hline 20 & $29 \cdot 6$ & $15 \cdot 7$ & $13 \cdot 9$ & 177 & $\cdot 0785$ \\
\hline \multirow[t]{2}{*}{60} & \multirow[t]{2}{*}{$20 \cdot 8$} & \multirow[t]{2}{*}{$14 \cdot 3$} & \multirow[t]{2}{*}{6.5} & 81 & $\cdot 0801$ \\
\hline & & & & Mean .. & $\cdot 0796$ \\
\hline
\end{tabular}

From the time-rate of the fall of temperature of the iron ring we may judge of the uniformity of temperature inside the sand-bath. The constant was assumed to remain the same till the 20th of the same month, when a sudden change, due to changes in the arrangement of magnets in the laboratory, was observed. The constant was redetermined as follows:- 
Determination of Thermoelectric Constant (April 20, 1888).

\begin{tabular}{|c|c|c|c|c|c|}
\hline Time. & $\begin{array}{l}\text { Temp, of } \\
\text { iron ring. }\end{array}$ & $\begin{array}{l}\text { Temp. of } \\
\text { wooden } \\
\text { ring. }\end{array}$ & $\begin{array}{c}\text { Difference } \\
\text { of tempo- } \\
\text { rature. }\end{array}$ & $\begin{array}{l}\text { Galvanometer- } \\
\text { deflexion. }\end{array}$ & $\begin{array}{c}\text { Difference of } \\
\text { temperature } \\
\text { corresponding } \\
\text { to onedivision } \\
\text { of galvano- } \\
\text { meter-deflex- } \\
\text { ion. }\end{array}$ \\
\hline $\begin{array}{lr}\text { h } & \mathrm{m} \\
3 & 16 \\
3 & 47 \\
4 & 15 \\
5 & 2\end{array}$ & $\begin{array}{l}5 \stackrel{8}{3} \cdot 4 \mathrm{C} . \\
47 \cdot 9 \\
42 \cdot 9 \\
36 \cdot 3\end{array}$ & $\begin{array}{l}16 \cdot 2 \mathrm{C} . \\
16 \cdot 5 \\
16 \cdot 4 \\
16 \cdot 3\end{array}$ & $\begin{array}{l}37 \cdot 2 \mathrm{C} . \\
31 \cdot 4 \\
26 \cdot 5 \\
2000\end{array}$ & $\begin{array}{l}458 \\
387 \frac{1}{2} \\
326 \\
245\end{array}$ & 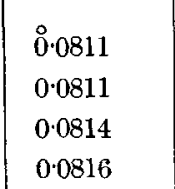 \\
\hline & & & & Mean ........... & 0.0813 \\
\hline
\end{tabular}

Hereafter the constant was tested every day by comparing the deflexion of the galvanometer caused by a permanent barmagnet placed at a definite place.

The experiment consisted in making three different determinations, i. e.:-(1) the strength of the alternating current from which the magnetizing field is calculated; (2) the rate of alternation per second of time ; (3) the rise of temperature of the junction at the iron ring above that at the wooden ring.

The alternating current was measured by a deci-ampere balance for small current, and by Siemens's dynamometer for large eurrent. The dynamometer was carefully compared with the ampere-balance, and its constant was $\cdot 878$ ampere per division. The rate of alternation was determined by means of a counter connected to the commutator, and it varied between 28 and 400 complete reversals per second. The difference of temperature was observed by the mirror-galvanometer in the thermoelectric circuit. In most cases several observations were made during one experiment, so that the rise of temperature of the iron ring above that of the wooden ring can be graphically represented. Sometimes only the final readings were taken, omitting the intermediate points : these are distinguished from others by simply connecting the final point to the origin by a dotted line. The figures from 1 to 19 represent the experiment.

From the foregoing description of the method of measuring the difference of temperature, it appears that if the thermal qualities of the two rings are exactly the same, there will be no difference of temperature between the two junctions so long as heat is supplied from the current only, and hence the difference of temperature between the tw'o junctions will indicate the heat due to the reversals of magnetization; in other words, Joule's effect will be entirely eliminated. 
It was found, however, in the course of experiment that when a continuous current was passed through both the rings, the tendency of the temperature of the thermo-junction at the wooden ring was to rise above that at the iron ring, principally due to the difference of thermal diffusivity. But when the current was made to alternate, this was entirely overmasked by the heat arising from reversals of magnetization.

Thus, in order to find how much heat is due to the reversals of magnetization, a proper amount of allowance must be made for the heat diffused and radiated. A satisfactory way of arriving at the rate at which heat is generated in the substance of iron would be to solve the general equation of the conduction of heat when part of the conducting medium is generating heat. Such an equation will be

$$
\frac{d v}{d t}=\kappa \nabla^{2} v+q / c,
$$

with proper boundary conditions as to time and space: $v$ being the temperature, $t$ time, $\boldsymbol{\kappa}$ diffusivity, $q$ the rate of generation of heat per unit volume per unit time, $c$ thermal capacity per unit volume.

Now when $q$ is constant and the sole source of heat,

$$
t=0, v=0 \text {, }
$$

and therefore

$$
\left(\frac{d v}{d t}\right)_{t=0}=q / c
$$

that is, the time-rate with which the temperature begins to rise is the true measure of the rate of generation of heat in the substance. As soon, however, as the elevation of temperature becomes sensible, heat will be diffused inside the body and radiated into the outside space. But whatever be the way in which heat is conducted in the body, when we consider the time-variation of temperature at a definite point in the body, the law of diffusion of heat will be expressed by

$$
\frac{d v}{d t}=q-h v ;
$$

where $h$ is a mixed coefficient depending upon conduction and emission, as the generating body is in contact with other conducting body as well as being exposed to the air. This mixed coefficient $h$ might be called dissipativity, as it measures the rate at which heat is taken away from the generating body irrespective of how it is done.

Putting the single letter $q$ for $q / c$ for convenience, the above equation with the initial condition $t=0, v=0$, gives

$$
v=\frac{q}{h}\left(1-e^{-h t}\right) \text {. }
$$

This will be strictly applicable to the rise of temperature in 
an infinitely thin wire through which current is made. Curves in fig. 21 give the rise of temperature thermoelectrically determined plotted against time, when a continuous current was sent through the copper coil of only one of the rings; the other being kept at the temperature of the room. They show how far the equation thus calculated is realized in experiment.

Expanding $v$ in powers of $t$, thus

$$
\begin{aligned}
v & =\frac{q}{h}\left(1-1+h t-\frac{h^{2} t^{2}}{\mid 2} \ldots\right) \\
& =q\left(t-\frac{h t^{2}}{2}+\frac{h^{2} t^{3}}{13} \ldots\right)
\end{aligned}
$$

we see that the time-rate of the rise of temperature at the beginning gives the rate of generation of heat independent of the dissipativity $h$, as was indicated by the general equation ; and, therefore, whatever the diffusivities of the wooden and iron rings may be, the heating-effect due to current alone would have been eliminated in the beginning, if only the rate of generation of heat had been the same in both rings; in other words, the curve of temperature growth would have begun tangent to the time-axis, when the same continuous current was sent through both the rings. Experiment revealed, however, that this was not the case; the curve of difference of temperature growth began with definite rate (see fig. 22), so that there must have been a difference in the rate of supply of heat in the two rings. This is very likely due to the difference in the resistance of wire used in winding the rings, or irregularities in the rate of winding in the neighbourhoods of junctions. Assume, therefore,

$$
\begin{aligned}
& v_{1}=q / h\left(1-e^{-h t}\right) \text { for the wooden ring, } \\
& v_{2}=q^{\prime} / h^{\prime}\left(1-e^{-h^{\prime} t}\right) \quad, \quad \text { iron ring; }
\end{aligned}
$$

taking their difference, we have

$$
v=v_{1}-v_{2} \text {, }
$$

which is observed in the thermoelectric current. From this we have

$$
\frac{d v}{d t}=q e^{-k t}-q^{\prime} e^{-h^{\prime} t},
$$

which shows that at the beginning the temperature rises at the rate $q-q^{\prime}$ per unit of time; and, further, the difference of temperature, $v$, is maximum when

$$
t=\log \left(\frac{q}{q^{\prime}}\right) /\left(h-h^{\prime}\right) ;
$$

and, therefore, there is or is not a maximum according as $q$ and $h$ are greater or less than $q^{\prime}$ and $h^{\prime}$ correspondingly or 
not. In the present case $q>q^{\prime}$, hence we infer that $h>h^{\prime}$ from the existence of a maximum. The point of inflexion in the temperature-curve is given by

$$
t=\log \left(\frac{q h}{q^{\prime} h^{\prime}}\right) /\left(h-l^{\prime}\right),
$$

which shows that when there is a maximum the point of inflexion takes place at a later period than the maximum.

The ultimate temperature when the current is kept running for a very long time is given by

$$
v=q / h-q^{\prime} / h^{\prime}
$$

and, therefore, we see that the curve does or does not cross the zero-line of temperature according as the ratio $q / h$ is $<$ or $>q^{\prime} / h^{\prime}$. See fig. 20, where the temperature of iron ring above that of wooden ring is taken positively.

So much for continuous current, that is, when the supply of heat is derived solely from the magnetizing solenoid, which forms a kind of anchor-ring shell. Now, when an alternating current is passed, the whole mass of the iron ring becomes a source of heat, which is the subject of the study. The dissipativity $h^{\prime}$ will no longer be the same as before; for the whole mass of iron, instead of conducting away heat from the surface shell, becomes a source of heat, and therefore, when its rate of generating heat is greater than that due to the current it gives heat to the outer shell.

Put $Q$ for the heat produced per unit time by reversals of magnetization, and $H$ the dissipativity at the point where the thermoelectric junction is placed, then

$$
\begin{aligned}
& v_{2}=\frac{\mathrm{Q}+q^{\prime}}{\mathrm{H}}\left(1-e^{-\mathrm{H} t}\right) \text { for the iron ring, } \\
& v_{1}=q / h\left(1-e^{-h t}\right) \quad, \quad \text { wooden ring. }
\end{aligned}
$$

Expanding $v_{1}$ and $v_{2}$ and subtracting,

$$
v_{2}-v_{1}=v=\left(\mathrm{Q}+q^{\prime}-q\right) t-\left\{\left(\mathrm{Q}+q^{\prime}\right) \mathrm{H}-q h\right\} \frac{t^{2}}{\underline{2}}+\ldots
$$

But $q$ and $q^{\prime}$ will have a constant ratio, as they are both proportional to the square of current, so that we may put

$$
q-q^{\prime}=a c^{2},
$$

and this is what is approximately true, as found by experiment (see fig. 22).

Also as $h$ and $H$ are constants, and $H<h$ and $q^{\prime}<q$, from the foregoing investigation we may put

$$
q^{\prime} \mathrm{H}-q h=-\beta c^{2} .
$$

Thus the rise of temperature of the iron ring above the wooden one, when the same alternating current is passed 
through both, can be expressed very approximately when time is sensibly small by

$$
v=\left(\mathrm{Q}-\alpha c^{2}\right) t-\left(\mathrm{QH}-\beta c^{2}\right) \frac{t^{2}}{\mid \underline{2}}+\ldots,
$$

whence we see that the temperature-curve bends toward or away from the time-axis according as QH is greater or less than $\beta c^{2}$. Now $Q$ depends upon the rate of reversals of magnetization as well as on the magnitude of the magnetic hysteresis. Hence we see that the temperature-curve is turned upward when $\mathfrak{H}$, the magnetizing field, is large compared with the hysteresis, and vice versâ. By referring to the figs. 1 to 20 , one sees now why some of them are curved upward while others are curved downward. The downward curvature only occurs when the hysteresis is large compared with the field $\mathfrak{H}$, that is in the steepest part of the curve of magnetization.

In order to find $Q$ from the observed data an empirical equation $v=\mathrm{A} t+\mathrm{B} t^{2}$ was assumed, and $\mathrm{A}$ was taken to be equal to $Q-\alpha^{2} c$ for each curve, instead of determining the tangent to the curve from $\mathrm{H} h q q^{\prime} c$. The equation will be true if the heat generated were immediately communicated to the thermo-junction. But on account of the cotton covering, which lies between the iron and the junction, there will be a slight time-lag for the temperature-bore to reach the junction. To take this into account another constant is added to the equation thus

$$
v=\mathrm{A} t+\mathrm{B} t^{2}+\mathrm{C} \text {. }
$$

This $\mathrm{C}$ will give the temperature which the ring would have had at the beginning if there were no time-lag; or it might otherwise be looked upon as a constant error in zero of the galvanometer.

The constant A was found for each curve from the observed data by the usual method of least squares. It was found, however, in the course of calculation that when the number of observations was only 3 or 4 , the three constants gave too much freedom to the curve; that is, the law of least squares is not nearly fulfilled by so few points. In other words, errors of observation rather tended to modify the form of the curve instead of compromising amongst themselves as would be the case when there are many. From this it was thought expedient to take the equation with only two constants, A, B, when there were less than 6 points (double the number of constants) in the curve, and three constants $\mathrm{A}, \mathrm{B}, \mathrm{C}$, when there were more.

The tangent $A$ thus found is now to be corrected for the differential Joule's effect, which was denoted by $a c^{2}$. Fig. 22 shows the curves of temperature growth when a continuous current of given strength was sent through both the rings, and

Phil. Mag. S. 5. Vol. 28. No. 172. Sept. 1889. R 
curves (fig. 23) show the integral amount of temperature corresponding to different currents after given time has elapsed, the ordinate being the reading of the Siemens dynamometer, which is proportional to $c^{2}$. The curves show that the difference of temperature due to Joule's effect is sufficiently expressed by the form $\alpha c^{2}$, where $\alpha$ is constant. From these curves the correction was found for each experiment, and $\alpha c^{2}$ is drawn below the time-ordinate in each curve by dashes (figs. 1-19); and the true rate of the generation of heat arising from the reversals of magnetization is taken to be the algebraic difference of the ordinate of the tangent at origin, and this line. It is seen that this term $\alpha c^{2}$ is so small, when $\mathfrak{S C}$ is less than 10 , that the line in the diagram is scarcely distinguishable from the time axis.

When the field $\mathfrak{H}$ was increased above 30 C.G.S. units, the heat due to the current alone was so great that a large part of the heat due to magnetic reversals was neutralized by it. Special experiments were made in which a continuous current was sent through both the rings for more than half-an-hour, when the time-variation of temperature became very small, and then the current was alternated. Fig. 20 shows three experiments of this kind. It is seen that in all the cases the effect of the continuous current was to heat the wooden ring; and when the current was alternated, the temperature of the iron ring rose suddenly almost in straight line. It must be remarked here that when the current was made to alternate its strength diminished, partly owing to induction and partly to the increase of contact resistance. In the curve corresponding to $\mathfrak{Y}=32 \cdot 8$ the heating-effect due to current was made to remain the same by suddenly taking off some resistance in the circuit at the instant of commencing the alternations. In other two this was not done: the difference can be seen from the values of $\mathfrak{S}$ given alongside the curves.

The rate of heating thus obtained was divided by the number of complete reversals per second to find the heat due to one complete reversal of magnetization. The temperatures so found are plotted against $\mathfrak{S}$ in fig. 27 , the number near the points gives the rate of alternations per second.

\section{Ballistic Experiment.}

In order to compare the heating-effect thus far obtained with the hysteresis in the same ring, the amount of magnetization was now investigated ballistically. For this purpose a secondary coil was wound uniformly over each of the rings, and the current induced by changes of magnetization in the iron ring due to small sudden changes of magnetizing field was measured by the throw of a ballistic mirror-galvanometer in the circuit. The secondary coil over the wooden ring was 
joined in series with that of the iron ring in such a way that the induced currents due simply to the magnetizing field $(\mathfrak{S})$ in the two rings will neutralize each other in causing the ballistic effect. This was of course a mere matter of convenience, as the irreversible part of the cycle of magnetization,

$$
\int_{-h}^{h}(4 \pi \mathfrak{S}+\mathfrak{S}) d \mathfrak{S}
$$

depends solely upon $\mathfrak{I}$ and not upon $\mathfrak{S}$.

The ballistic galvanometer was one of Sir William Thomson's design, used some years ago for investigating dynamical qualities of metals. The period of its swing was made longer by loading the aluminium frame of the needle. The proportionality of the throw was tested by slipping off suddenly some temporarily formed loops of moderately fine copper wire from a permanent bar-magnet. This showed that the throw varied according to the number of these loops throughout the extent of the scale as far as the accuracy of the experiment could allow.

The magnetizing field, that is the field due to the primary coils of the rings, was varied by small sudden steps by increasing the conductivity of the circuit. This was accomplished hy putting a number of Edison lamps in the circuit, arranged as in the so-called Mho-box. The strength of the current was measured after each step by a deci-ampere balance in its circuit.

The value of the change of magnetization of the iron wire corresponding to one division of the ballistic throw was determined by putting an earth induction-coil in the galvanometer circuit and observing the throw when the coil was quickly turned. The coil was wound upon a circular wooden frame provided with proper axis: its dimensions were as follows:-

Diameter of the frame . . . . .

Diameter of the coil after winding the wire

30.5 centim.

Number of turns of wire in the coil (8 layers of 27 turns each) . . .

Sum of areas of all the turns . . 167640 sq. centim.

Resistance of the coil (at $11^{\circ} \mathrm{C}$., room's temperature)

Resistance of the galvanometer . . $\quad \cdot 634 \mathrm{ohm}$.

Resistance of leading wires . . . $\quad .229 \mathrm{ohm}$.

So that, when the experiment with the earth induction was made, the circuit had the total resistance of . 
Horizontal intensity of the earth's field . $\cdot 152$ C.G.S.

Ballistic throw caused by one complete revolution of the coilabout a verticalaxis fixed in the plane of the coil . . . . 15 scale-divns.

This was mean of five observations agreeing amongst themselves within $\frac{1}{2}$ division.

Number of turns of the secondary coil over the rings . . . . . . . .

Total area of the sections of iron wire in the ring, $130 \times \frac{\pi}{4}(\cdot 115)^{2}$. . . . $=1.35$ sq. centim.

Resistance of the secondary coils . . . $605 \mathrm{ohm}$.

Resistance of the galvanometer . . . $\cdot 634 \mathrm{ohm}$.

Resistance of the leading wire. . . . $229 \mathrm{ohm}$.

Whence the total resistance in the circuit when the change of magnetization was experimented upon . . . . . 1.468 ohm.

From those numbers the value of $\mathfrak{J}$, the intensity of magnetization corresponding to one division of the ballistic throw is

$$
\frac{167640 \times 2 \times 152}{15 \times 1 \cdot 35 \times 100 \times 4 \pi} \times \frac{1 \cdot 468}{5 \cdot 169}=\cdot 569 \text { in C.G.S. }
$$

Figs. 24, 25, 26 show the curves of magnetization when the magnetizing field $\mathfrak{S}$ was cyclically varied between given limits. Each curve consists of two consecutive cycles; the points belonging to the first cycle are marked by dots, and those belonging to the second by crosses. The areas of those cycles $\int \mathfrak{I} d \mathfrak{S}$ were calculated by Simpson's method, and gave severally

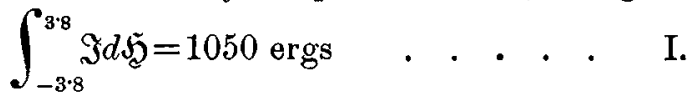

$$
\begin{aligned}
& \int_{-8^{* 6}}^{8 \cdot 6} \Im d \mathfrak{S}=6690 \quad \text {. . . . . . II. } \\
& \int_{-21}^{21} \mathfrak{J} d \mathfrak{S}=13610, " \cdot . \quad \cdot \quad \cdot \quad \cdot \quad \text {. III. }
\end{aligned}
$$

The ring was now undone and 33.4 centim. of the iron wire was cut off, straightened and annealed, and then the curve of magnetization was studied by the magnetometric method. The result was anticipated in Phil. Mag. Nov. 1888, p. 450, in connexion with another research, where

$$
\int_{-51}^{51} \Im d \mathfrak{S}=18450 \text { ergs. . . . . . IV. }
$$

Now if the whole work so done upon the substance of iron oy cyclic change of magnetization be assumed to be used up 
entirely in heating the iron, the rise of temperature will be obtained by dividing the number of ergs by Joule's equivalent and the heat-capacity of the iron per unit volume. Taking -11 for the specific heat, 7.7 for the density, and $4.16 \times 10^{7}$ as Joule's equivalent, we have

$$
1 /\left(\cdot 11 \times 7 \cdot 7 \times 4 \cdot 16 \times 10^{7}\right)=2^{\circ .84} \times 10^{-8} \mathrm{C} \text {. per erg. }
$$

Whence we get the rise of temperature corresponding to the above values:- I. . . $0.30 \times 10^{-4} \mathrm{C}$.

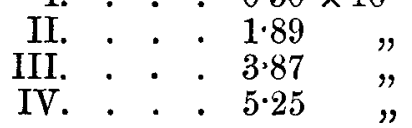

The temperatures thus calculated are plotted in fig. 27 in encircled points. It is there seen that the curve thus obtained lies above that obtained by direct thermometric measurement. The difference will of course be partly due to experimental imperfection, and partly to uncertainties in the assumed constants, and finally to the real cause, if there is any.

One apparent term neglected in the calculation, from the want of numerical result in literature, is the heat taken by the cotton covering of the iron wire. This cotton was found by weighing separately to be $\cdot 72$ per cent. of the iron by weight. The effect of introducing this correction will be slightly to lift up the points in the figure 27. But even if we assume its specific heat to be as much as that of water, it will not be enough to make up the difference.

Another point to be remembered is that the magnetizing field in the direct thermometric experiment was deduced from the square root of the readings of an idiostatic galvanometer, which gives the mean square of an alternating current; while in the ballistic and magnetometric experiments the field was directly determined. Now when the magnetization is effected gradually or by steps, the hysteresis depends upon the maximum field to which the iron is subjected (or the limits of cycle), so that in comparing the energy in hysteresis with the heating effect caused by alternating field, we ought to have taken the maximum fields in the course of alternations instead of the mean square root. It was found during the experiment that when an E.M.F. of 100 volts with high resistance was used, the current, when alternating, was little above 80 per cent. of what it was when the alternator was stopped. From this we may infer that the mean square root is not very far from the maximum value we are after ; and if we imagine each point in the curve of heating observed in fig. 27 to be somewhat shifted towards the right, they would not be far from corresponding to what actually took place.

The effect of temperature in changing the magnetic quality of 
the iron is entirely neglected, as it has been found by many experimenters to be very small when the temperature is less than $100^{\circ} \mathrm{C}$. or so.

Putting aside these considerations for the time being, the experiment, imperfect as it is, seems to indicate that a large part (about 80 per cent.*) of the energy involved in hysteresis is used in heating the substance of iron; that the speed with which the cycle is performed has very little effect upon hysteresis, that is within 28 and 400 complete periods per second; that soft iron takes in $\frac{1}{400} \mathrm{sec}$. at least more than 70 per cent. of the magnetization it would have when subjected to the field for hours.

Two curves (fig. 28) are added, as calculated from Prof. Ewing's paperst, one for very soft iron and the other for tempered pianoforte steel. The curve for soft iron will be seen to lie lower than the observed temperature in the present experiment, and in the steel the heating is seen to be more than six times that for soft iron.

[A somewhat more accurate method of measuring this dissipated energy has been thought of, and approved by Sir William Thomson. It is hoped that the work will be undertaken before long and more satisfactory results arrived at.]

XXX. Notices respecting New Books.
Graphics, or the Art of Calculation by Drcuing Lines, applied espe-
cially to Mechanical Engineering; with an Atlas of Diagrams. By Prof. R. H. Smith. Part I. (Longmans, 1889.)

THE author observes that "this book will not enable the student of Practical Mechanics to dispense with the use of other books treating mechanics in the ordinary manner." After reading his work, we say that this witness is true. What, then, is the writer's intention? "It [the book before us] is intended to enable those who have a knowledge of elementary mechanics to advance that knowledge to any degree of thoroughness they may find useful, and to apply that knowledge to the everyday problems of engineering science, without the aid of the more complicated portions of algebraic and trigonometrical Mathematics, or of the differential and integral calculus. Many have no taste or faculty for this latter sort of Mathematics; others have not the time needed to keep them au fait in its use; and, again, it is undeniably true that the solution of many a problem becomes practicable in point of time and ease by the graphic method which would be intolerably tedious and difficult without its aid." We remember hearing, some eighteen years since, Prof. Crofton explain some diagrams he had drawn in illustration of a paper on the "Stresses in Warren and Lattice

* Profs. Warburg and Hönig, by calorimetric method, find the directly observed heat to be from 60 to 70 per cent. of the amount calculated from hysteresis in bar-magnets. (Wied. Ann. 1883, p. 814.)

+ Phil. Trans. part ii. 1885. The numbers for soft iron are taken from p. 556 , and those for the steel calculated from the diagram in fig. 16 of pl. 60 . 
Plit. Mas. S. 5. Vol. 28 . PI. VI.
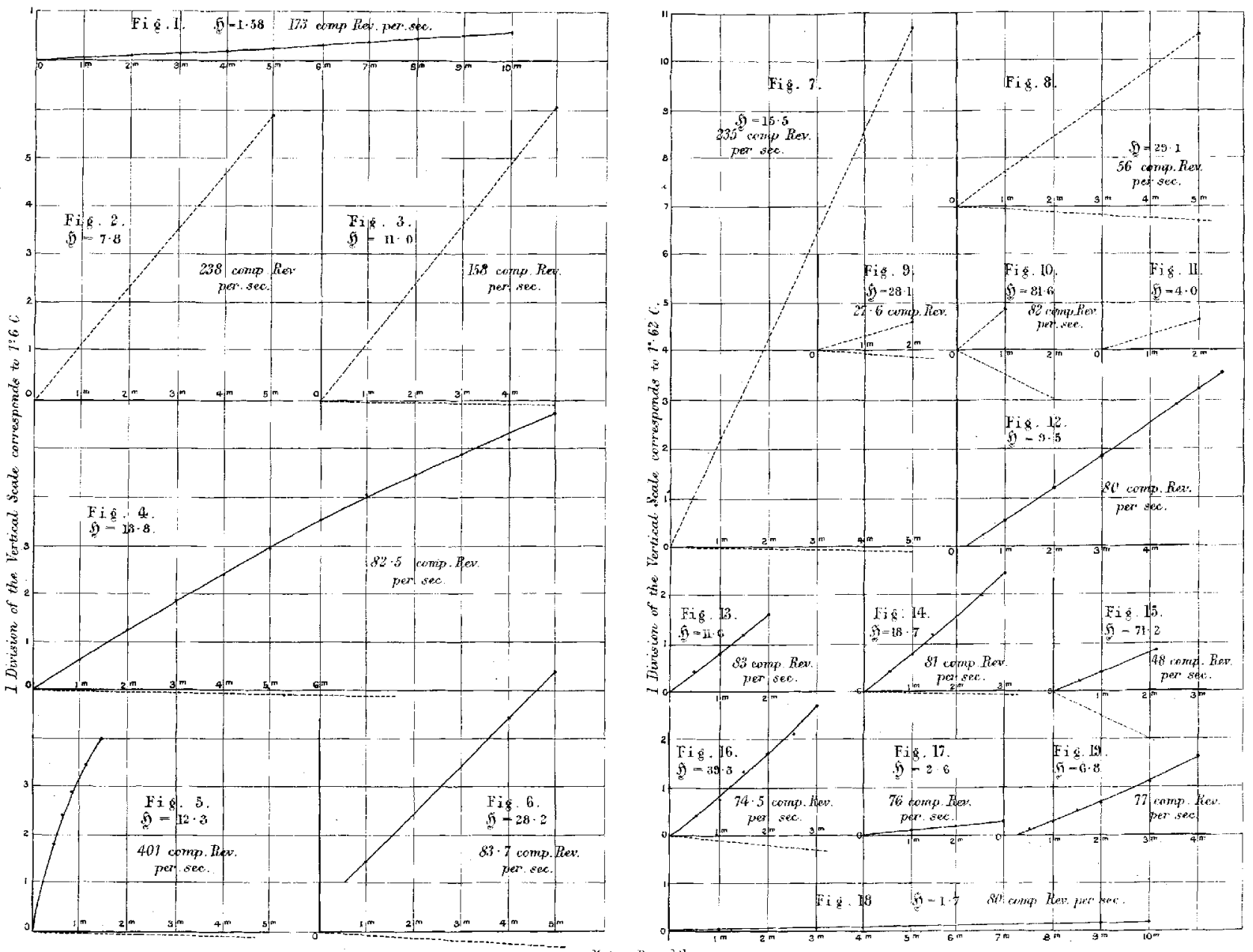

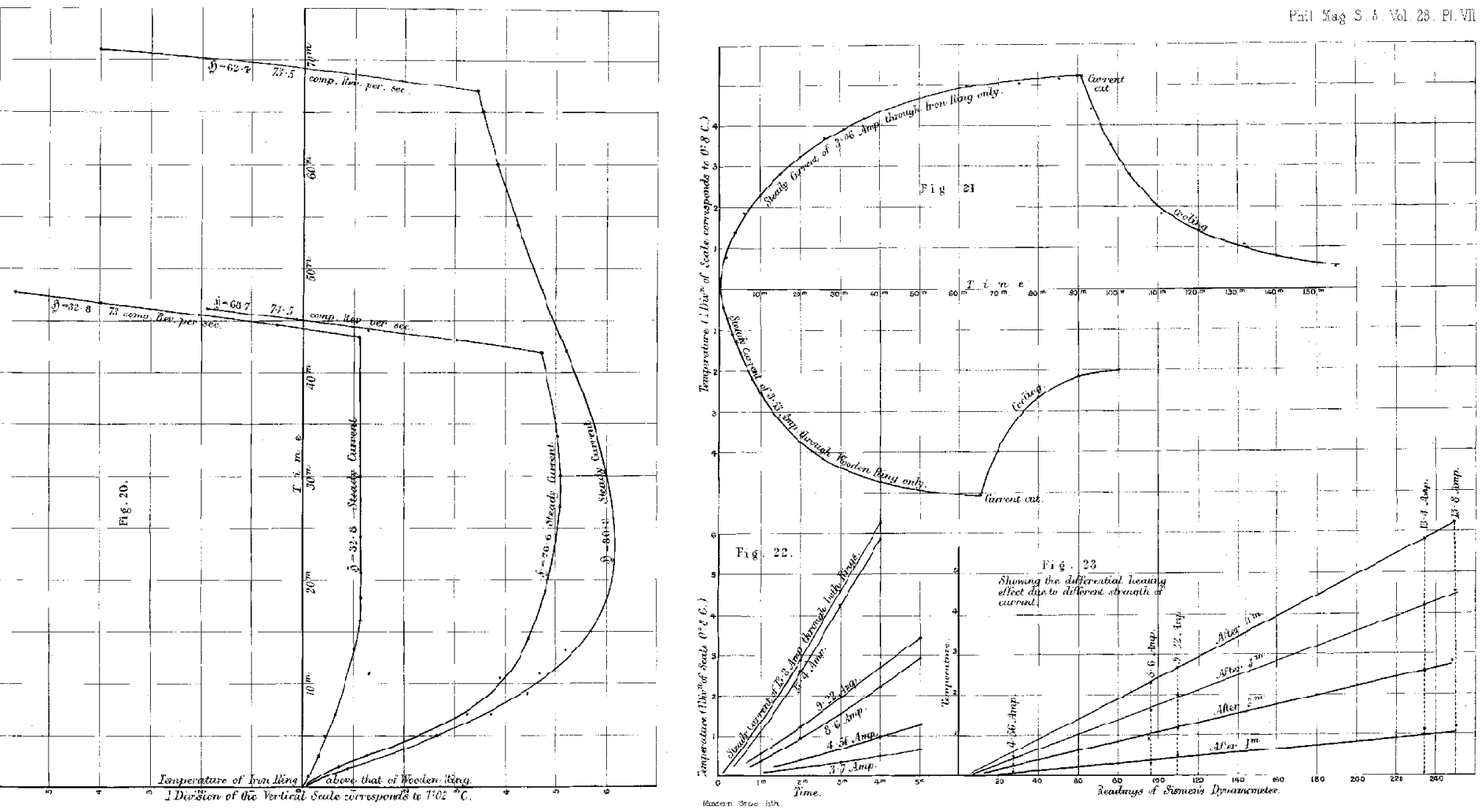

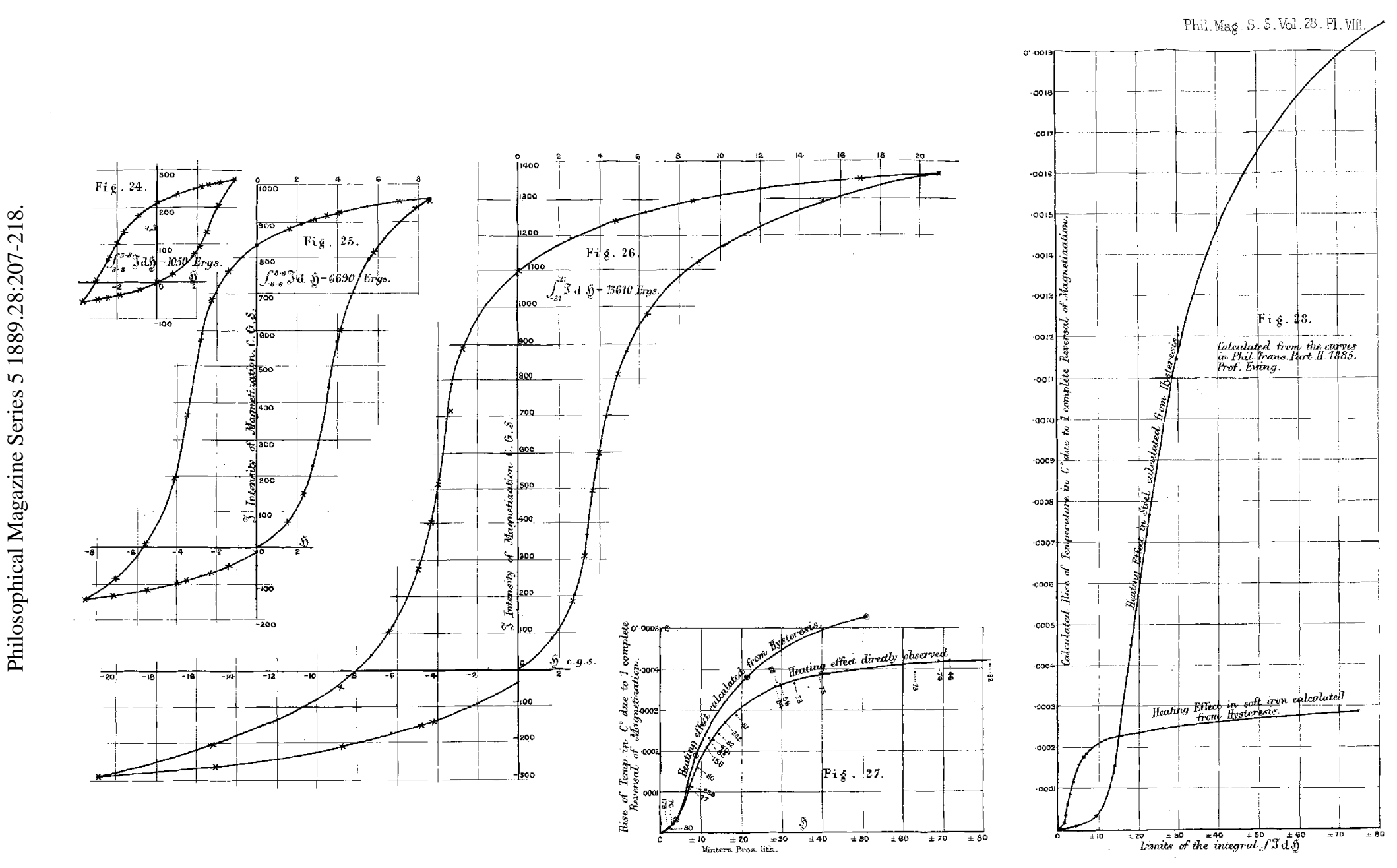